\title{
BDN programmes and the effect of medical students' interventions to promote child health in Sudan
}

\author{
S.H. AbdelRahman, ${ }^{1}$ I.M. Albashir, ${ }^{2}$ S.A. Hussein, ${ }^{1}$ M.E. Ahmed, ${ }^{1}$ S.M. Alfadil ${ }^{3}$ and
} N. Mohamed ${ }^{4}$

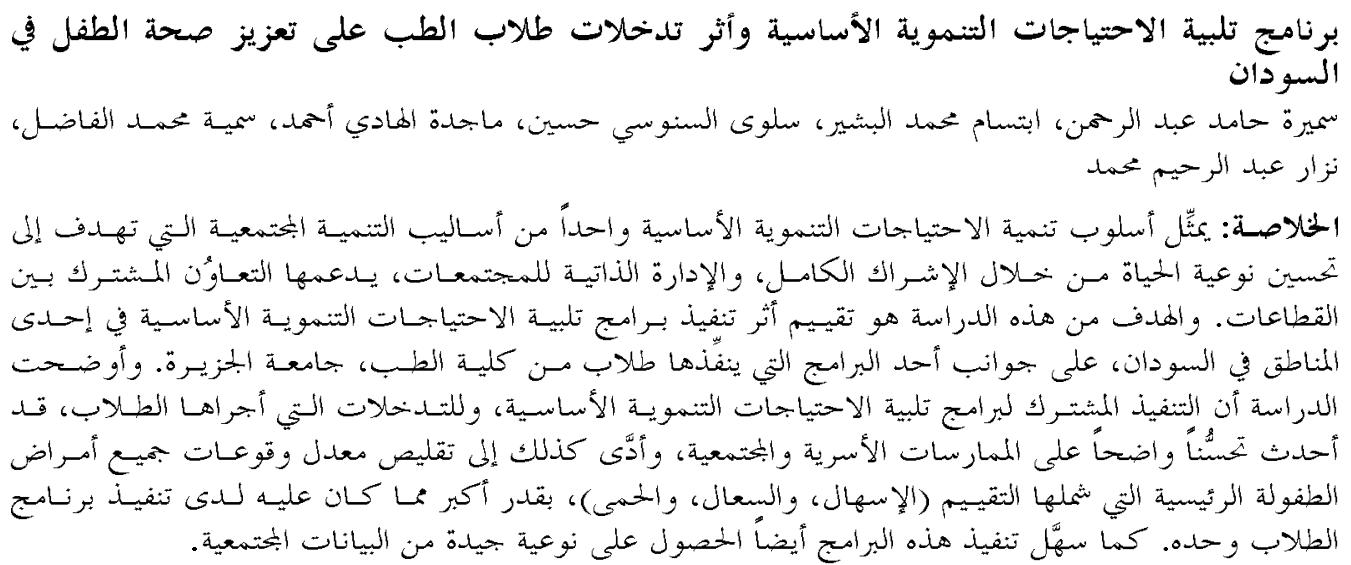

ABSTRACT Basic development needs (BDN) is an approach to community development that aims at improving quality of life through the full involvement and self-management of communities, supported by intersectoral collaboration. The objective of this study was to assess the effects of BDN implementation in an area of Sudan on aspects of a programme implemented by students from the Faculty of Medicine, University of Gezira. The study revealed that the joint implementation of BDN programmes and students' interventions brought about marked improvement of family and community practices as well as greater reduction in the incidence of all assessed major childhood illnesses (diarrhoea, cough and fever) than when the students' programme was implemented alone. BDN implementation also facilitated the retrieval of good quality community-based data.

Les programmes des besoins fondamentaux en matière de développement et l'effet d'interventions des étudiants en médecine dans la promotion de la santé infantile au Soudan

RÉSUMÉ La satisfaction directe des besoins fondamentaux d'une communauté est une stratégie de développement communautaire visant à améliorer la qualité de vie d'une population par le biais de l'implication totale et de l'autogestion des communautés, soutenues par une collaboration intersectorielle. Cette étude avait pour objectif l'évaluation des effets de l'application des stratégies BDN [pour basic development needs] dans une région du Soudan sur les différents aspects d'un programme mis en oeuvre par les étudiants de la Faculté de Médecine de l'Université de Gezira. Cette étude a révélé que l'application conjointe de programmes BDN et d'interventions d'étudiants en médecine a induit une franche amélioration des pratiques familiales et communautaires, ainsi qu'une diminution plus nette de l'incidence de l'ensemble des principales maladies infantiles évaluées (diarrhée, toux et fièvre), comparativement à la seule intervention des étudiants. Les programmes BDN ont également facilité la récupération de données de qualité sur les différentes communautés.

${ }^{1}$ Department of Community Medicine, Faculty of Medicine, University of Gezira, Wad Medani, Sudan (Correspondence to S.H. AbdelRahman: samhamid2002@yahoo.co.uk).

${ }^{2}$ Ministry of Health, Gezira State, Wad Medani, Sudan.

${ }^{3}$ World Health Organization, Khartoum, Sudan.

${ }^{4}$ World Health Organization, Tehran, Islamic Republic of Iran.

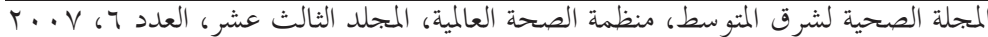




\section{Introduction}

Basic development needs (BDN) is a comprehensive approach to community development that aims at improving the quality of life of communities through their full involvement, self-management and selfreliance, supported by intersectoral collaboration. Local management of $\mathrm{BDN}$ projects focuses on community organization, mobilization, capacity-building and needs-based bottom-up planning that supports intersectoral collaboration in the attainment of overall community development.

A BDN programme was first set up in Sudan in 1980 as a pilot programme. In 1997 the World Health Organization, in coordination with the Federal Ministry of Health, started an organized, structured implementation. In Gezira state, the programme has been implemented since 2001 in a model area (Um-Alghora locality, 1 of 7 areas in Gezira state) and later in 2 other areas (South Gezira and Almanagil).

The Faculty of Medicine, University of Gezira, was established in Wad Medani town, the capital of Gezira state in 1975. It adopts the philosophy of community orientation aiming at solving community problems. Thus, it implements an innovative problem-solving, integrated, student-centred community-based educational programme. Community-based courses comprise $22 \%$ of the total credit hours of its curriculum. The Faculty has actively participated in different programme activities throughout all phases of the evolution of BDN in Gezira, such as: training of technical support teams, village development committees and cluster representatives; community mobilization; and supervision of community surveys.

The interdisciplinary field training research and rural development (IDFTRRD) programme is a community-based course offered to medical students at the end of the summer semester (in the 2nd, 4th and 6th semesters). Its main aim is to provide practical field training for students in rural communities. The organization of the module is as follows. Groups of 15-18 students are posted to a village (with a population of at least a few hundred to few thousand) where they conduct field activities, supervised by a group of university staff members. The students are responsible for the development of their assigned village. The module consists of 3 phases:

- Phase 1: Students collect basic sociodemographic information and other data to identity priority developmental problems and to plan and design projects to investigate the causes of these problems with a view to identifying solutions.

- Phase 2: Students analyse data, draw conclusions and implement a projecttargeted solution for the selected problem(s), with the full involvement of the community and through mobilization of necessary resources from different sectors.

- Phase 3: Students follow up their projects and make an evaluation of the outcomes and impact of their project and other related activities.

During their stay in the village in the 3 phases of the module, students usually conduct different activities aiming at the improvement of community health. Such activities include: 1-day clinics, sessions addressing prevailing health problems, cleaning campaigns, planting of trees and health education on issues such as immunization, breastfeeding, use of insecticidetreated bednets, correct nutritional practices and so on. They also engage the community in many cultural, sports and recreational activities.

The objective of this study was to investigate the effect of students of the Faculty of Medicine, University of Gezira on various indicators of community development 
in Um-Alghora. A comparison was made between areas where BDN had been implemented before the University's IDFTRRD programme and areas where the students implemented the IDFTRRD programme alone to investigate the effect of $\mathrm{BDN}$ on various indicators of community development, the participation of local communities in students' activities and on students' access to and quality of data collected at community level.

\section{Methods}

\section{Study design}

A cross-sectional study design was adopted where the study population was students from the Faculty of Medicine, University of Gezira, implementing the IDFTRRD programme in 2 groups of villages of UmAlghora area. Data collected as part of this study followed a prospective interventional longitudinal study design where the study population was families in the study area with children aged under 5 years.

\section{Study areas}

The study areas were 2 groups of villages in Um-Alghora area.

Group 1 comprised 4 villages (Ragwa Bakir, Ragwa Ahmed, Dahawi Bakir and Dahawi Karor), with a total population of 5000. This area hosted the students' IDFTRRD programme, and was also an area where the BDN community-based initiative had been introduced in the year 2001 . As part of the BDN initiative, 86 incomegenerating projects (mainly breeding of cows and goats) were owned by local families. Cluster representatives also received training on family and community practices according to the integrated management of childhood illnesses (IMCI) approach plus vocational training on food processing and handicrafts. A training package for volunteers prepared by the Federal Ministry of Health was utilized for this purpose. The trained cluster representatives conducted training of community members within their clusters. For this they used the training module for community volunteers on key family and community practices, which is part of the IMCI community component (also prepared by the Federal Ministry of Health), as the IMCI programme was introduced into the area in 2001.

Group 2 comprised 3 villages (Almaiaa, Ghifar and Ki'wirra) that also hosted the students' IDFTRRD programme, but where the BDN project was not implemented. Villages were selected by stratified random sampling from the 3 administrative units in the Um-Alghora area. The total population in the 3 villages was 15000 .

Pre- and postintervention surveys were conducted in the 2 groups of villages in phase 1 and 3 of the students' training, utilizing a standardized questionnaire that is routinely used by the students during the IDFTRRD programme.

From each group of villages, 100 families with children aged under 5 years were included in the study. The families were selected by simple random sampling. The questionnaire was designed to assess the knowledge, attitudes and practices of the family (mainly mothers of children aged under 5 years) that affect the health of their children, and the morbidity rate due to diarrhoea, cough and fever among those under 5 years. The study variables included:

- Socioeconomic characteristics of the study population.

- Improvements in the health practices of families. These were assessed by students through the utilization of the Sudanese adapted IMCI mother card. Improvements were identified by comparing results of pre- and postintervention surveys regarding a number of

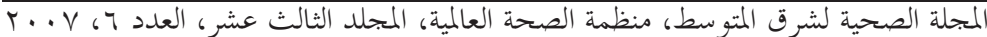


indicators: \% of under $5 \mathrm{~s}$ not vaccinated at all, $\%$ of under $5 \mathrm{~s}$ up-to-date with their vaccination, $\%$ of families utilizing regular growth monitoring services, \% of pregnant women utilizing antenatal services, $\%$ of married women using oral contraceptives for family planning, $\%$ of under $5 \mathrm{~s}$ up-to-date taking vitamin A supplements, \% of under 5 s sleeping under insecticide-treated bednets.

- Improvement in the health status of the under $5 \mathrm{~s}$. A comparison was made preand postintervention of $\%$ of families seeking care from a professional health worker for an under 5 with an episode of diarrhoea, cough or fever during the past 2 weeks.

- Assessment of community participation in the students' programme.

Data were also collected from all student groups who were posted as part of the IDFTRRD programme in group 1 and group 2 villages. The data collection was done immediately after students returned from the villages to the university campus. A structured pretested questionnaire was used to assess:

- Participation of community members in the students' activities and interventions such as the survey, project, cleaning campaign, 1-day clinic and tree planting.

- Students' access to and quality of the data collected by them at the village level. Student's assessment of community participation and data were indicated on a 3-point scale (0-2), where 0 indicated poor and 2 indicated good.

\section{Data analysis}

Data was entered and analysed using SPSS, version 10. All percentages were obtained through the program. The difference between percentages was tested using nonparametric tests, mainly binomial based on the Z-test, to find out if there were significant differences.

\section{Results}

\section{Sociodemographic characteristics}

There were no statistically significant differences in the distribution of age, educational status and occupation among the parents and caretakers of children aged under 5 years in the 2 groups of villages (data not shown).

\section{Improvements in family and community practices}

In group 1 villages most of the preintervention indicators for students' interventions were better than those of group 2 villages, a situation that could be attributed to the previous implementation of BDN in the group 1 villages. Furthermore, the effect of student's interventions on improving family practices was more marked in BDN villages in comparison with their effect in villages not implementing BDN (Table 1).

The students' impact was higher in BDN villages with regard to the following objectives of their interventions:

- Reduction of percentage of families with children under 5 years who were not vaccinated at all.

- Increase in percentage of families with children under 5 years who were up-todate with their immunizations.

- Increase in percentage of families utilizing regular monthly growth monitoring services.

- Increase in percentage of married women utilizing antenatal care services.

- Increase in percentage of married women in childbearing age using oral contraceptives for family planning. 
Eastern Mediterranean Health Journal, Vol. 13, No. 6, 2007

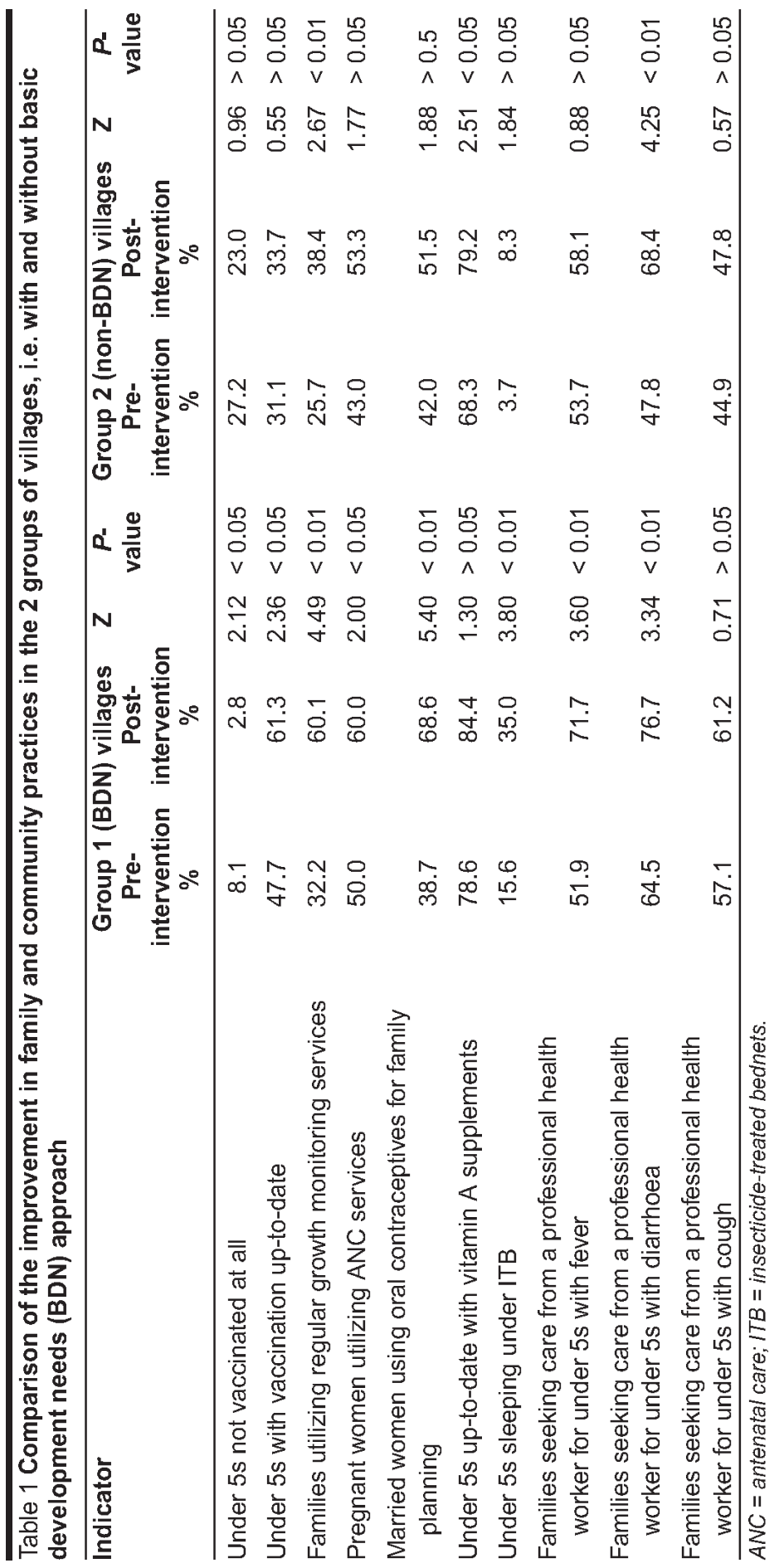

المجلة الصحية لشرق المتوسط، منظمة الصحة العالمية، المجلد الثالث عشر، العدد Y، V... 
- Increase in percentage of families with their children under 5 years sleeping under insecticide-treated bednets.

- Increase in percentage of families seeking care from a professional health worker for their children under 5 years who had fever.

- Increase in percentage of families seeking care from a professional health worker for their children under 5 years who had diarrhoea.

- Increase in percentage of families able to perform correct nutritional practices for feeding their children under 5 years.

The effects of students' interventions in non-BDN villages was only higher with regard to the following objectives:

- Increase in percentage of families whose children under 5 years were up-to-date with supplementary doses of vitamin A.

- Increase in percentage of families who seek care from a professional health worker for their children under 5 years with cough.

\section{Health status of under-5-year-olds}

The reduction in the occurrence of diarrhoea and cough among the under $5 \mathrm{~s}$ was more marked in group 1 villages, whereas the reduction in the occurrence of fever was more marked in group 2 villages. In group 1 villages the incidence of diarrhoea in the pre-intervention period (17.2\%) was even lower than the postintervention levels observed in group 2 villages (21.2\%), an effect that could be attributed to the BDN programme. Although the reduction in the occurrence of fever among under $5 \mathrm{~s}$ was larger in group 2 villages, the postintervention level was still lower in group 1 villages (11.2\%) compared with group $2(16.1 \%)$ (Figure 1).
Community participation in students' interventions

Table 2 presents a comparison between the number of community members (both sexes) who participated in different student activities in group land 2 villages. No specific denominator was identified to transfer the frequencies of participating community members into percentage indicators. However, in view of the total population in each of the 2 groups of villages (5000 in group 1 and 15000 in group 2 and the almost equal numbers of participating individuals we can conclude that, overall, the community participation of group 1 villages was far greater than that of group 2 villages.

The most notable difference between the 2 groups of villages was the participation of women in group 1 villages. The number of women participants in the 2 groups was almost equal in activities such as the students' survey, tree planting and cleaning campaigns. The women in group 1 villages were organized and active as cluster representatives. They came out to welcome the students on their arrival to the villages and participated with the students in different parts of their project. Students described women from group 1 as "active and committed to developing their villages".

Regarding the students' access to and quality of data collected, families and community members in both groups of villages were very ready to provide students with the required sociodemographic data. Students commented that community members in group 1 villages were more cooperative and could understand students' requests more easily. The data of group 1 villages was more organized and complete than that of group 2 villages. Village information centres had been established in group 1 villages as part of $\mathrm{BDN}$ implementation and some trained cluster representatives assisted students in their surveys. 


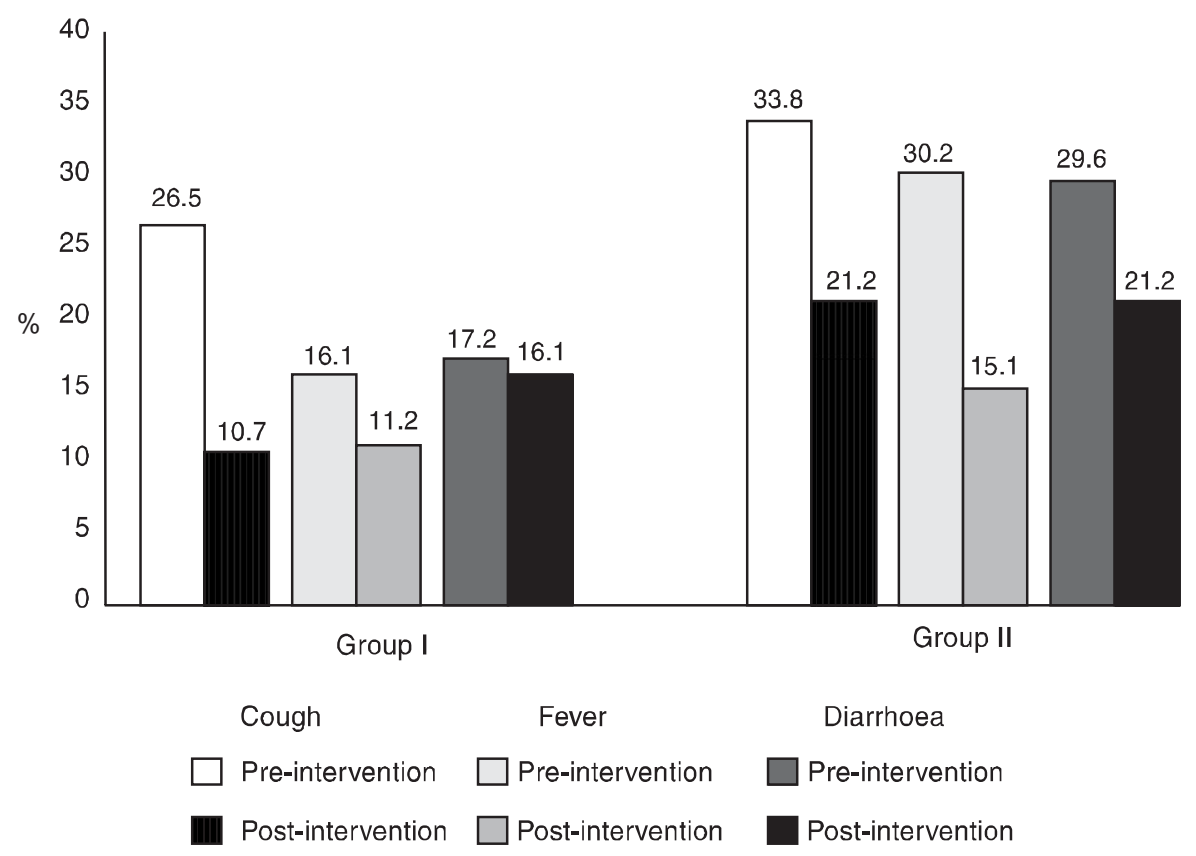

Figure 1 Occurrence of cough, fever and diarrhoea in children aged under $\mathbf{5}$ years in the 2 groups of villages

\section{Discussion}

As community-based interventions, both the BDN and students' activities of the university IDFTRRD programme, are based on similar principles as follows:

Organizing the community for promoting partnership for self-development. BDN works through organization of the community into clusters and formation of village development committees. Students in the IDFTRRD programme also mobilize and work in the community through its existing organizations such as peoples' committees, students' unions, etc. They also address community leaders (traditional and religious) whose status and role in their communities cannot be overlooked. However, students working in non-BDN villages noted that villages expressed a willingness and commitment to organizing communities in a similar way to BDN villages in any future community-based projects.

Capacity-building of local communities. Both BDN and the university IDFTRRD programmes aim to achieve sustainable development and not only the provision of transient urgent services. Training of village development committees and cluster representatives in the BDN programme contributes effectively to raising social awareness of the community, enhancing self-reliance and thus ensuring sustainability of developmental activities. The involvement of communities by students throughout all phases of their programme has also contributed to raising the social and health awareness of villages.

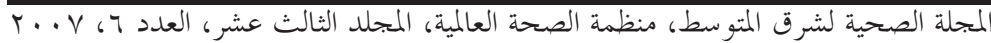




\begin{tabular}{|c|c|c|c|c|}
\hline \multirow[t]{2}{*}{ Activity } & \multicolumn{2}{|c|}{$\begin{array}{c}\text { Group } 1^{\mathrm{a}} \\
\text { (BDN) villages }\end{array}$} & \multicolumn{2}{|c|}{$\begin{array}{c}\text { Group 2a } \\
\text { (non-BDN) villages }\end{array}$} \\
\hline & $\begin{array}{c}\text { Women } \\
\text { No. }\end{array}$ & $\begin{array}{l}\text { Men } \\
\text { No. }\end{array}$ & $\begin{array}{l}\text { Women } \\
\text { No. }\end{array}$ & $\begin{array}{l}\text { Men } \\
\text { No. }\end{array}$ \\
\hline Welcoming students to the village & 8 & 10 & - & 18 \\
\hline Students' survey & $32^{\mathrm{b}}$ & 57 & 14 & 60 \\
\hline Students' project & 6 & 15 & - & 7 \\
\hline Cleaning campaign & 51 & 78 & 57 & 78 \\
\hline Organization of the 1-day clinic & 7 & 21 & 2 & 6 \\
\hline Tree planting & 44 & 56 & 52 & 73 \\
\hline
\end{tabular}

Improving the behaviours and health status of local communities. Health education was provided by trained cluster representatives to communities in group 1 villages. The community members in both groups of villages received organized education and training by the medical students who were formerly trained in IMCI family and community practices as part of the Faculty of Medicine curriculum. It is to be noted that house-to-house distribution of vitamin A doses had stopped in Gezira state in the period 2000-02. Students have thus promoted community-based distribution of vitamin A capsules.

Emphasis of comprehensiveness and multidisciplinary development. The important role of government and other sectors in different stages of developmental projects is addressed in BDN through involvement of trained technical support teams. Students' analysis of community problems has also enabled community members to realize the different determinants of health and illness and to identify the roles of relevant sectors in the solutions to their problems.
Although behaviour change usually takes a long time to be established, the results of the study showed a significant improvement, with varying degrees, in all the measured behavioural and health indicators in the 2 groups of villages. Evaluation of BDN programmes in many countries has demonstrated similar effects. In Yemen [1], where the tetanus toxoid coverage was previously low, the BDN intervention improved the situation considerably and resulted in a slight increase in the status of immunization and a slight decrease in the percentage of deaths in infants. In Djibouti [2], the principal effect of the BDN programme in the field of health has been the prevention of diseases through community health volunteers who educate communities about school health, immunization, nutrition, environmental health, prevention of malaria and HIV/AIDS. As a result, infant mortality, immunization coverage among infants (1 month to 1 year), percentage of children under 5 years followed for growth monitoring and percentage of women immunized against tetanus showed vast im- 
provements against the national averages. In Jordon, the quality of life project villages also demonstrated improved utilization of family planning, antenatal care coverage (almost 100\%), together with an increase in the expanded programme of immunization coverage, through health awareness sessions and motivation of mothers through community representatives [3].

The community-based training programme of the Faculty of Medicine, University of Gezira, sets a good model for how to adjust health manpower development to the real health needs and demands of the population and the national health system, which was formerly identified as the "health manpower development concept" [4].

Community-oriented medical education was first defined in the first meeting of the network of community-oriented educational institutions for health sciences in 1979 as "a type of training of health personnel that focuses on both population groups and individuals and that takes into account the health needs of the community concerned" [4].

The community-based education that is adopted by the Faculty of Medicine, University of Gezira, represents a tool to achieve the faculty objectives through students' postings in the community. Community-based education in itself is thus a means of achieving educational relevance to community needs and, consequently, a way of implementing the faculty's community-oriented educational programme [5].

The IDFTRRD programme implemented in Um-Alghora has satisfied the rationale of community-based education for the following reasons:

- Education of students during their residence in the community is an established approach to training doctors who are willing and able to work in underserved areas, particularly rural communities [6]. In addition, our students have the opportunity to learn, in real-life situations, about different communitybased programmes such as BDN and the IMCI community component. Students in group 1 villages appreciated the role of BDN in community organization and awareness.

- During their posting, students deliver health education sessions and discuss the results of the health surveys with the community, including analysis of the causes and impacts of different community problems and needs. All these opportunities can enhance students' learning, as information is better understood, processed and retrieved if students have opportunities to elaborate on that information [5].

- Students posted in Um-Alghora have contributed to the availability of health services in the villages, ranging from curative services (1-day clinics) to promotion and preventive services such as health education, cleaning campaigns, tree planting and distribution of vitamin A capsules. This should be considered as an active contribution from our students to solving the problems of service delivery in those rural areas and to the improvement of the health system, as it works towards resolving priority health problems of the population [7].

- During their posting in villages or assignments in rural health facilities, students have had opportunities to practice a multidisciplinary and holistic approach to health care $[8]$.

This educational programme of the Faculty of Medicine, University of Gezira, thus provides an excellent model for partnership between the community, the university and the government, being an advanced step in collaboration between the 3 parties, a goal that BDN aims to achieve in creating part-

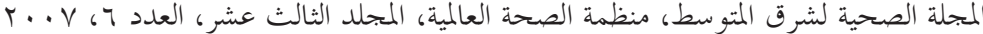


nerships between communities and relevant sectors.

\section{Community participation}

Important determinants, which constitute preconditions, for community participation, include:

- Commitment of the professionals who engage in the process.

- Competences in areas such as communication and facilitating and managing change, to ensure effective work with and between decision-makers, middle managers, community leaders and community members.

Both preconditions were ensured by the BDN approach, through the commitment of higher-level and local authorities (by the commitment of technical support teams and training in BDN strategies and methods). As for student activities, the following factors and conditions coexisted:

- Commitment of the top administrators in the University of Gezira who conducted field visits and meetings with community leaders to express the university commitment to supporting students' activities.

- Faculty of Medicine staff conducted preliminary visits to all the concerned villages prior to each phase of the IDFTRRD programme to seek the permission of the community and to orient community leaders with the course objectives and the students' tasks.

- Field visits by Faculty of Medicine staff to supervise students' activities.

- Faculty of Medicine students usually receive training in communication skills as part of the faculty curriculum programme. In addition, students also learn about legal aspects of the medical profession and professional ethical principles regarding medical practice at individual, family and community levels.

- Faculty of Medicine staff (from the Department of Community Medicine) have participated as part of Gezira state BDN steering committee and core of trainers in the planning and implementation of all the project activities: training of technical support teams, village development committees and cluster representatives; community mobilization; and monitoring and follow-up of the project activities. This role puts the Faculty of Medicine more in touch with the community and its leaders in BDN (group 1) villages.

All these factors provide a favourable environment for community participation in students' activities in Um-Alghora, especially in BDN villages. It is well recognized that involving communities in assessing their own needs and assets is a key component of the overall planning process, often providing a starting point for community participation by increasing the understanding of both professionals and the community and enabling more responsive and participatory policy-making and service delivery [9]. Such involvement in the implementation, monitoring and evaluation stages were ensured by both the BDN project and the students' project in group 1 villages. The population of group 1 villages, exposed to the experience with the BDN project, were already organized and enabled in issues concerning quality of life and comprehensive development.

\section{Conclusion}

The study revealed that the collective implementation of community-based programmes such as BDN and students' interventions 
brought about marked improvements in family and community practices and greater reductions in the incidence of all assessed major childhood illnesses (diarrhoea, cough and fever) than with the students' programme alone. It also demonstrated that BDN implementation resulted in an organized and ready-to-mobilize community in addition to the availability of easily retrieved and good quality community-based data.

\section{Recommendations}

- BDN areas should be the focus of all community-based health activities organized by different sectors (including academic institutions).
- Introduction of BDN concepts and strategies in the curricula of medical schools and other health professional training institutes.

- Adoption of community-based education as an educational strategy in different training institutes for health professionals.

- Medical students in phase 1 of their IDFTRRD programme should organize communities according to the BDN strategy, in order to facilitate positive interaction and community participation.

- Continuous research to measure the effect of BDN and medical students in promoting family and community practices and assess the different factors influencing these practices.

\section{References}

1. Evaluation of the basic development needs programme in the Republic of Yemen. Cairo, World Health Organization Regional Office for the Eastern Mediterranean, 2005.

2. Evaluation of the basic development needs programme in Djibouti. Cairo, World Health Organization Regional Office for the Eastern Mediterranean, 2005.

3. Appraisal of basic development needs initiatives in Jordan. Amman, Jordan, World Health Organization, 2003.

4. Fulop T, ed. Health personnel for tomorrow: the great challenge of the health for all movement. Manila, World Health Organization Regional Office for the Western Pacific, 1985 (WRP/HMD/INF 4.4).

5. Magzoub ME. Studies in communitybased education programme implementation and student assessment at the Faculty of Medicine, University of Gezira,
Sudan, 1994 [Doctoral thesis]. Maastricht Rijksuniversiteit Limburg, 1994

6. Magnus $\mathrm{JH}$, Tollan A. Rural doctor recruitment: does medical education in rural districts recruit doctors to rural areas? Medical education, 1993, 27:250-3.

7. Abdel Rahim IM, Mustafa AE, Ahmed BO. Performance evaluation of graduates from a community-based curriculum: the horsemanship period at Gezira. Medical education, 1992, 26:233-40.

8. Hamad B. Interdisciplinary field training research and rural development programme. Medical education, 1982, $16: 105-7$.

9. Community participation in local health and sustainable development. Approaches and techniques. (European Sustainable Development and Health Series 4). Copenhagen, World Health Organization Regional Office for Europe, 2002 (EUR/ ICP/POLC 060305D rev. 1). 